\title{
Erratum to: Re-Irradiation: New Frontiers
}

\section{Carsten Nieder and Johannes Langendijk}

The original version of the book has been revised: The chapter source lines of all the chapters has been updated to Medical Radiology - Radiation Oncology

The updated original online version for this chapter can be found at

DOI 10.1007/174_2016_59

DOI 10.1007/174_2016_60

DOI 10.1007/174_2016_34

DOI 10.1007/174_2016_62

DOI 10.1007/174_2016_55

DOI 10.1007/174_2016_71

DOI 10.1007/174_2016_66

DOI 10.1007/174_2016_33

C. Nieder, MD $(\triangle)$

Department of Oncology and Palliative Medicine,

Nordland Hospital, Bodø, Norway

e-mail: Carsten.Nieder@nordlandssykehuset.no

J. Langendijk, MD

Department of Radiation Oncology, University

Medical Center Groningen/University of Groningen,

Groningen, The Netherlands 
DOI 10.1007/174_2016_76

DOI 10.1007/174_2016_48

DOI 10.1007/174_2016_61

DOI 10.1007/174_2016_77

DOI 10.1007/174_2016_75

DOI 10.1007/174_2016_56

DOI 10.1007/174_2016_67

DOI 10.1007/174_2016_47

DOI 10.1007/174_2016_57

DOI 10.1007/174_2016_37

DOI 10.1007/174_2016_32

DOI 10.1007/174_2016_72

DOI 10.1007/174_2016_58

DOI 10.1007/978-3-319-41825-4 